\title{
Procesos y lógicas de las urbanizaciones cerradas en áreas metropolitanas: Bogotá, Colombia y Buenos Aires, Argentina
}

\author{
Processes and Logics of closed urbanizations in metropolitan areas: Bogotá, \\ Colombia and Buenos Aires, Argentina
}

Alejandro Mendoza Jaramillo, ${ }^{1}$ M.Sc.

${ }^{1}$ Universidad Nacional de Colombia. Bogotá, Colombia. Correspondencia: almeja05@gmail. com

Recibido: 31 de Julio de 2016. Aceptado: 5 Septiembre de 2016.

Mendoza, A. (2016) Procesos y lógicas de las urbanizaciones cerradas en áreas metropolitanas: Bogotá, Colombia y Buenos Aires, Argentina. Procesos urbanos Número 3, Ene-Dic. 55-78. Doi:10.21892/2422085X.267

\section{RESUMEN.}

El presente artículo hace un breve recorrido por las lógicas y procesos en torno a uno de los fenómenos de ocupación del suelo más difundidos en las ciudades latinoamericanas Urbanizaciones Cerradas (UC) -, aterrizado en las áreas metropolitanas de Bogotá y Buenos Aires. En este sentido, se busca develar las particularidades y similitudes en la instalación de ese producto inmobiliario y su posible incidencia en la configuración de dos metrópolis, leído a través de tres dimensiones (crecimiento poblacional, instalación de UC y configuración urbana).

Palabras clave: Urbanizaciones cerradas, áreas metropolitanas, ciudad latinoamericana.

\begin{abstract}
The present article makes a brief tour of the logics and processes around one of the phenomena of land occupation most widespread in the Latin American cities -Closed Urbanizations (UC)-, landed in the metropolitan areas of Bogota and Buenos Aires. In this sense, we seek to uncover the peculiarities and similarities in the installation of this real estate product and its possible impact on the configuration of two metropolis, read through three dimensions (population growth, UC installation and urban configuration).
\end{abstract}

Keywords: Closed urbanizations, metropolitan areas, Latin American city. 


\section{INTRODUCCIÓN: EL PATRÓN DE CONFORMACIÓN PROPIO DE LA CIUDAD LATINOAMERICANA}

El crecimiento urbano ha sido caótico y desbocado en la mayoría de países latinoamericanos, aun con los esfuerzos que los gobiernos locales hicieron para controlar la localización de ciertos usos y gestionar de manera significativa la producción del territorio. Al respecto, algunos investigadores aplicaron desde diferentes perspectivas, modelos clásicos para explicar las dinámicas que definen la estructura urbana actual de las ciudades latinoamericanas. Borsdorf (2003) Janoschka (2002) y Jaramillo (1993, 1999) desarrollaron algunos modelos con los cuales intentaron interpretar las dinámicas urbanas que las particularizan, descubriendo entre otros factores, la importancia que tuvieron las migraciones rural-urbano, la inadecuación de las relaciones sociales de producción de tipo tradicional, la primacía de la ciudad capital frente al resto urbano (macrocefalia), los fuertes cambios demográficos, la presencia de amplias zonas rurales con economía de subsistencia, el acelerado crecimiento de la red urbana, el elevado grupo de personas en situación de vulnerabilidad social, además de la fuerte marginalidad física y segregación urbana.

El proceso intensivo de urbanización constituyó un signo distintivo de las ciudades latinoamericanas, además de una serie de dinámicas que la configuraron y permiten comprenderla, aun con las adaptaciones propias que se pudieron suceder: las ciudades se convirtieron en grandes metrópolis gracias al aumento de su tamaño físico y a la inversión hecha para mejorar la velocidad de los flujos en la comunicación y el transporte físico (con el uso de ferrocarriles en un primer momento y de vías pavimentadas posteriormente). Buzai (2006) destaca que el cambio del modelo de extensión urbana tradicional -herencia de la Colonia- hacia el patrón de crecimiento fragmentado, típico de la ciudad norteamericana, fue común a todas las ciudades latinoamericanas a partir de la década del cuarenta (pues es en este momento en el que se verifica la expansión moderna e intensiva de los centros urbanos de comercio a través de la construcción de grandes edificios, centros comerciales y hoteles).

La explosión de la mancha urbana que borró las fronteras de los municipios aledaños y la ciudad central, formó conurbaciones gigantescas ${ }^{1}$. Ello evidenció dificultades para llevar a cabo instancias de concertación que desembocaran en una gestión urbanística metropolitana, como consecuencia del involucramiento de un creciente número de jurisdicciones locales. Asimismo, la híper concentración de servicios (financieros, administrativos, educativos, telecomunicaciones, entre otros), la interdependencia para la disposición de los recursos naturales que les son comunes a las entidades y la intensiva localización de diversos usos del suelo de manera indiscriminada o descontrolada (urbanizaciones cerradas -en adelante $\mathrm{UC}^{2}$-, parques industriales, grandes equipamientos), se constituyeron en factores debilitantes o de riesgo que se potenciaron con la ocurrencia del proceso mencionado.

Ahora bien, bajo un patrón de crecimiento urbano que seguía los ejes de empleo y transporte, resultó que "las oscilaciones presentes que se producen en el tamaño poblacional de un espacio urbano, además de sus patrones de movimiento, producto de la redistribución de las actividades de la población y el empleo, plantearon la necesidad de un rasgo más amplio y variado de modos de transporte y servicios" (Correa y Rozas, 2006: 17). La aceleración en los ritmos de transporte y la masificación del automóvil, tuvieron una incidencia importante sobre la escala interurbana, dado que fue posible la extensión de los espacios superándose la planeación de actividades con base en el factor proximidad espacial. Con esto se abrieron múltiples opciones para escoger la

\footnotetext{
1 Esto explica por qué algunas de las formaciones metropolitanas más reconocidas de la región se constituyen funcionalmente mas no jurídicamente, pues en la mayoría de los casos, ocurrió que la ciudad central o de importancia económica, política y social, imprimió unas fuertes lógicas metropolitanas a las dinámicas urbanas propias de cada municipio de su entorno (por ejemplo el rol de ciudades dormitorio o un sistema vial de interconexión en forma radial).

$2 \mathrm{~A}$ los fines del artículo, por UC se comprenden aquellos resultados o productos inmobiliarios del proceso urbanizador llevado a cabo principalmente por agentes privados, cuya característica distintiva es el cercamiento físico que sirve para la delimitación de fronteras, sin importar sus dimensiones, equipamientos internos, densidad, valor del suelo o de los requerimientos para la compra de una vivienda, siendo el cerramiento físico la única condición excluyente.
} 
Mendoza, A. - Procesos y lógicas de las urbanizaciones cerradas en áreas metropolitanas.

localización de las actividades en función a la movilidad y conectividad disponibles con los sitios claves del tejido urbano. Es decir, se consolidó "un modelo de desarrollo urbano fundamentado en la extensión urbana, vías de comunicación rápidas, autopistas rápidas y una nueva polarización organizada alrededor de los centros comerciales en la periferia" (Dureau et al, 2000: 41).

De manera complementaria, las ciudades latinoamericanas sufrieron y aún hoy mantienen unos matices intensivos de fragmentación social, los cuales están relacionados con los procesos económicos característicos del sistema económico mundial de tipo capitalista. Como consecuencia de ello, se encuentran fenómenos tan disímiles ocurriendo en un mismo marco temporal, como lo ejemplifica la desurbanización y la privatización residencial. Por ello, distintos autores formularon y utilizaron un nuevo modelo que fuese más explicativo de las particularidades latinoamericanas: la ciudad fragmentada ${ }^{3}$.

A mediados del siglo $X X$ se generaron nuevos imaginarios de los suburbios, con los cuales se transforma la asociación preexistente de lo periférico como lugar destinado a los pobres, para centrarse esencialmente en sus ventajas de naturalidad -idea de la libertad y de conexión con la naturaleza- y de distanciamiento con la ciudad -conservando las ventajas tecnológicas y las comodidades urbanas-, por lo que al tiempo que se reforzaba la inaccesibilidad se estimulaba la exclusión auto inducida, con la cual distinguirse del resto de la ciudad. Entonces, en esos nuevos suburbios se buscó articular lo atractivo de la vida rural con la cotidianidad urbana -pues no se realizan las tradicionales labores rurales-, como lo demuestran los proyectos residenciales de tipo privado que proliferaron intensivamente en las zonas periféricas de la ciudad: las UC.

3 Bajo tal concepto se refiere no solo al rasgo físico que prima en la actualidad en todas las ciudades de la región, sino que contiene implícitamente, la noción de la fuerte polarización social que las caracteriza. Buzai (2006) señala entre otras características, una fuerte heterogeneidad en las características poblacionales, la fuerte fragmentación urbana interna con límites urbanos poco definidos, la emergencia en todo el territorio de usos del suelo que son discrepantes con los modelos tradicionales, y la definición funcional de un centro altamente especializado, caracterizado además por ser el sector con mayor accesibilidad de la urbe -es origen y destino de gran parte de las rutas del transporte público-.
Autores como Carballo y Chevalier (2005), Delaunay y Dureau (2004), Dureau y Gouëset (2007), Lancioni et al (2012), Szajnberg (2005) y Torres (2001) han desarrollado investigaciones muy nutridas en las cuales describen con lujo de detalles el proceso suburbanizador que experimentaron algunas áreas metropolitanas como consecuencia de la instalación de UC. Según ellos, sus características estructurales -sensación de libertad a través de una amplia extensión física en la cual priman el contacto con la naturaleza y las relaciones detipo comunitario, todo enmarcado en circuitos de vigilancia y un encierro perimetral- fomentaron una acelerada suburbanización e impactaron en forma negativa sobre diversos aspectos del territorio y de la estructura urbana existente, en virtud de que su intensiva construcción durante las últimas décadas, incidió en la expansión de la mancha urbana sobre el territorio, empeoró las condiciones ambientales, paisajísticas y productivas de las zonas implicadas, así como planteó serios problemas de integración y comunicación entre los sectores de la ciudad ${ }^{4}$.

Bajo estas lógicas, se desarrollaron nuevos barrios que contaban con todos los servicios propios de una ciudad pequeña -lugares de esparcimiento, equipamientos colectivos y la posibilidad de generar fuentes de empleo-, y que poseían una nueva autonomía administrativa frente al gobierno local, representado en la prestación de los servicios básicos y de las garantías de ordenamiento y seguridad: "el barrio como la representación de la ciudad que anhelan, es una micro-ciudad armónica de paisajes verdes, agradables, tranquila, que ellos han construido, un entorno que contrasta con la otra gran ciudad y que lo muestra más humana y agradable de vivir" (Guerrero, 2006: 114). Así, cobran especial importancia una serie de atributos en y de la vivienda, tales como vigilancia, conexión vial, encerramiento, equipamientos deportivos y amplios espacios verdes. Las personas que deseaban vivir en los nuevos

4 Al respecto, Dureau, Barbary y Lulle (2007) señalan que los esquemas de segregación se acentuaron con la densificación de las ciudades a partir de su crecimiento acelerado, incidiendo principalmente en el componente residencial de la división social del espacio; esto en virtud de que en el mercado del suelo es en donde se refuerzan tales patrones, por cuanto se favorece una producción de espacios diferenciados para cada grupo poblacional con base en su desigual acceso y en la calidad de sus equipamientos urbanos. 


\section{Procesos Urbanos N³ Enero - Diciembre; 2016}

emplazamientos residenciales cerrados, que concibieron como ventajosa la concentración de servicios para evitar los desplazamientos a otros barrios de la ciudad, reforzaron el estilo de vida individualista en desmedro a la de corte barrial. El aislamiento ideológico y físico significa además la materialización de sueños por parte de los inversionistas pues la seguridad en la participación con iguales, identidad a través de grupos reducidos (status) e individualidad-anonimato (un mínimo de contacto vecinal), se emplazan en la mentalidad urbana contemporánea.

Ahora bien, estos cerramientos constituidos principalmente por la funcionalidad habitacional, "hacen que la ciudad cerrada permanezca indisociablemente ligada al resto de la metrópolis, sobre la que descarga una parte de las funciones urbanas para evitarse molestias: las actividades de producción y consumo" (Thuillier, 2005: 12). De manera que jalonan el crecimiento demográfico de sus alrededores, en donde además forman nuevas centralidades periféricas, que en ciertos casos no cuentan con las condiciones o equipamientos necesarios para cumplir con su nuevo papel (brindar aquellos servicios que demandan los habitantes de las UC cercanas).

En América Latina, las UC han sido fruto del cruce entre los modelos europeos y estadounidenses: México, Venezuela y Colombia son ejemplos más puros de las UC inspiradas en el modelo norteamericano de vivienda unifamiliar y de seguridad privada. Por su parte, los países del cono sur, entre ellos la Argentina, presentaron un desarrollo mucho más tardío y entremezclado con el modelo europeo de los "country clubs". Esto ocurrió, según Svampa (2001), gracias a la relativa homogeneidad social y al fuerte arraigo de una cultura más igualitaria en tales países: las representaciones sociales de igualdad que jugaron un papel importante en el contexto argentino, se vieron enarboladas por y desde las clases medias, en su mayoría inmigrantes, y desde los gobiernos de finales del siglo XIX hasta mediados del XX. Sin embargo, a partir de la dictadura militar y con la concreción del modelo aperturista posterior, la disolución del imaginario permitió el desarrollo desenfrenado de las UC inspiradas en el modelo norteamericano.

\section{METODOLOGIA}

En cuanto a la propuesta metodológica e instrumental, se considera la investigación desde una perspectiva hipotética-deductiva por lo que se remite a un estudio comparado de estudios de caso, seleccionados de entre otros tantos posibles, a fin de vislumbrar las convergencias y divergencias en los actores, lógicas y procesos que se pueden encontrar frente al fenómeno territorial de las UC en las dos áreas metropolitanas seleccionadas. El método de análisis elegido en esta investigación, estudio comparado de estudios casos, se caracteriza porque está basado en observaciones hechas sobre dos recortes geográficos, lo que permite reforzar su profundidad, pero limitando considerablemente la generalización de los hallazgos. Sin embargo, cabe señalarse que el hecho de que se haga una cuidadosa selección de los casos de estudio a analizar y de las dimensiones de análisis utilizadas, asegura que las conclusiones a las que se arribe tengan mayor fiabilidad $y$, de paso, sirvan como sustituto del control experimental o estadístico más amplio.

En la selección de las áreas metropolitanas a comparar se consideró lo señalado por Mesa-Lago (2002), según el cual, en las comparaciones internacionales se pueden seguir distintos criterios de selección. En el caso particular de esta investigación se optó por el criterio geográfico, de manera que se elaborara una comparación intrarregional, eligiendo al subcontinente suramericano en virtud de que es una región que ofrece algunas similitudes (en lo que hace a lenguaje, cultura e historia), pero que al mismo tiempo, ofrece un abanico amplio de procesos históricos particulares y diferenciados a cada país.

La selección de las dos áreas metropolitanas correspondió con la necesidad de seleccionar unidades territoriales que compartieran algunas características y que sus diferencias no constituyeran importantes barreras para realizar una comparación, para que se pudieran considerar como las más parecidas posibles de manera que se asegurase que las reflexiones finales no estuvieran sesgadas. En este sentido, se tuvo en 
Mendoza, A. - Procesos y lógicas de las urbanizaciones cerradas en áreas metropolitanas.

consideración el crecimiento poblacional de las dos metrópolis, que representasen el centro político, económico y social de mayor importancia a nivel nacional de cada país (en ambos están localizadas las ciudades capitales), son entidades consideradas 'ricas' en virtud de que aportan considerables recursos al erario nacional vía recaudación tributaria además de que cuentan con los mejores indicadores de calidad de vida en comparación con sus promedios nacionales. Así, se eligieron las áreas metropolitanas de Bogotá (AMB) y Buenos Aires (AMBA).

Ahora bien, para hacer la comparación de los procesos de instalación de UC y su posible incidencia en la configuración metropolitana, se consideraron tres dimensiones analíticas: crecimiento poblacional, instalación de UC y configuración urbana. Estas se construyeron agrupando los temas generales que desarrollan los principales autores en la materia (contienen las subdimensiones o aspectos básicos) y su finalidad es hacer una descripción a profundidad para cada metrópolis, para luego estructurar la lectura comparativa.

En este punto hay que señalarse que la elección del fenómeno de las UC como tema de apoyo, corresponde con la necesidad de tomar un fenómeno urbano que fuese ampliamente difundido y que tuviera presencia en las dos áreas metropolitanas elegidas. Así, aunque existen otros productos inmobiliarios que también hubieran podido servir para el mismo fin, cada uno con sus especificidades ${ }^{5}$, la relación entre la configuración de las áreas metropolitanas y las UC constituye en un tema cuya complejidad requiere seguir desarrollándose y hacer algunos comentarios desde perspectivas analíticas nuevas. A su vez, cabe destacarse que no se considera que la instalación de UC en el territorio sea el único factor determinante en la configuración de las áreas metropolitanas, pues al contrario, ese formato inmobiliario parece responder a las dinámicas estructurales señaladas más arriba; sin embargo se quería revisar

5 Otros fenómenos urbanos que hubieran servido para el mismo fin, son los enclaves comerciales de gran escala como los hipermercados, shopping center y los parques industriales periféricos, pues además de esta presentes en los dos países, también son productos que proliferaron en el tejido suburbano metropolitano. su incidencia sobre los territorios y si se evidenciaban rasgos comunes y particulares para las metrópolis elegidas que fuesen interesantes de destacar. Debido a la amplitud de las transformaciones ocurridas durante los últimos años o décadas en las dos áreas metropolitanas (en aspectos como lo socioeconómico y político-institucional), en el presente artículo se van señalando algunos temas a medida que se describen las dinámicas de configuración propias en cada área metropolitana, sin profundizar en cada transformación, pues ese tipo de análisis hace parte de otra bibliografía más específica y extensa.

La hipótesis que fundamenta la investigación es que se evidencia la consolidación de características comunes en la ocurrencia del fenómeno urbanístico específico -UCque inciden en la configuración de las áreas metropolitanas de Bogotá y Buenos Aires. Sendos procesos a su vez, significan retos comunes a las administraciones locales de los territorios. El objetivo principal del presente artículo es presentar, de manera sintética, la relación existente entre un fenómeno urbanístico específico y su impronta en la configuración de dos áreas metropolitanas de Latinoamérica, revelando a través de una lectura comparativa, las convergencias y divergencias en la ocurrencia del fenómeno para ambas metrópolis. En este sentido, también se intenta ampliar el campo de conocimiento existente sobre el desarrollo urbano de las ciudades latinoamericanas a través de una comparación internacional, con la intención de conocer hasta qué punto tales áreas comparten de manera simétrica la ocurrencia de algunos procesos urbanos.

Frente a las fuentes de información, la investigación se apoyó en las fuentes de segundo tipo, de forma que se consultó la bibliografía referente en el tema además de información estadística para verificar las dinámicas poblacionales. Finalmente, el orden expositivo del texto es el que sigue: en los dos primeros apartados se hace una lectura vertical sobre la configuración urbana de las dos metrópolis en relación con el fenómeno inmobiliario, descrito en las dimensiones arriba señaladas. En el siguiente apartado se hace la lectura

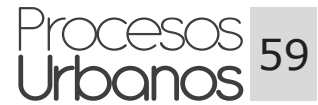


horizontal o comparativa de los aspectos principales para luego presentar algunas reflexiones finales sobre los principales problemas y retos que tienen los gobiernos locales de las dos áreas metropolitanas. Por cuestiones de espacio, las descripciones, el análisis comparativo y la formulación de resultados se presentan de forma sintética y acotada, aunque se recomienda consultar las referencias bibliográficas al final del texto para profundizar en los temas tratados.

\section{RESULTADOS}

\section{ÁREA METROPOLITANA DE BOGOTÁ (AMB)}

Una primera definición del área metropolitana de Bogotá (AMB en adelante), permite entenderla como la composición urbana que totalizaba una población de 8.760.731 personas en el año 2011 y que integra a la capital de la República de Colombia y a 17 municipios circunvecinos, pertenecientes administrativamente al departamento de Cundinamarca (ver Anexo 1). De estos, solo presenta conurbación o continuidad urbana con el municipio de Soacha, al sur. El AMB se distingue por tener una ciudad núcleo (Bogotá) y tres centros subregionales (municipios de Soacha, Zipaquirá y Facatativá).

Bogotá, al albergar las principales actividades productivas, sociales, políticas y culturales del país, se convirtió en polo de atracción para las distintas corrientes migratorias nacionales, alcanzando a representar al $14 \%$ de la población colombiana en 2005. Ello la constituyó en una ciudad con una importante influencia sobre los municipios que la rodean.-

\section{Crecimiento poblacional}

El componente demográfico es un importante factor explicativo de la intensa expansión que mostró la mancha urbana bogotana hasta la década del setenta, momento a partir del cual, con el efecto de la transición demográfica y la disminución en la intensidad de los flujos migratorios nacionales dirigidos hacia la ciudad, Bogotá entró en un proceso 60 Urocesos más pausado de crecimiento -alrededor del $3 \%$ anual-, acompañado de la transferencia del incremento poblacional hacia los municipios vecinos: en el período intercensal 1985-1993, el crecimiento de población de la periferia metropolitana fue dos veces mayor al de Bogotá y diez veces mayor al de otros municipios del departamento de Cundinamarca. Entre los años 1993 y $2005^{6}$, el área metropolitana de Bogotá pasó de 5.596 .626 a 7.881 .156 personas (un aumento del 40,8\%); mientras que para el año 2011 , alcanzaría a las 8.760 .731 personas (un incremento del 11,2\%). Si se considera la variación interanual de los años 1993 y 2011, se nota entonces que la población del AMB aumentó un 56,5\% (ver Figura 1).

El mencionado dinamismo poblacional hace pensar que en el corto y mediano plazo, Bogotá seguirá creciendo en los próximos veinte años a tasas más elevadas que las del departamento de Cundinamarca; el área metropolitana (Bogotá más municipios) seguirá creciendo más que Cundinamarca y Bogotá, y que los municipios metropolitanos en su conjunto crecerán a tasas más elevadas que la región y Bogotá: "la tasa para el lapso 2015-2020 se espera que sea del 30,44\%" (Alcaldía Municipal de Chía, 2005: 7). En el mismo sentido, el Departamento Administrativo Nacional de Estadísticas (DANE) proyecta que la población para el año 2030 de los municipios metropolitanos -sin contar a Bogotá-, alcanzará los 3 millones y medio de habitantes, es decir, tendrá la población actual de la ciudad de Medellín.

\section{Instalación de UC}

Como es de esperarse, las dinámicas de crecimiento poblacional estuvieron ligadas a la expansión de la mancha urbana, y las primeras fueron suficientes para que el frente de urbanización de la ciudad pasara los límites del Distrito y se extendiera sobre los unicipios de la sabana7. De allí se explica

\footnotetext{
6 Bogotá, al albergar las principales actividades productivas, sociales, políticas y culturales del país, se convirtió en polo de atracción para las distintas corrientes migratorias nacionales, alcanzando a representar al $14 \%$ de la población colombiana en el año 2005.

7 Autores como Delaunay y Dureau (2004), Dureau y Gouëset (2007) y Alfonso (2009) resaltan la intensificación de la expansión suburbana en los últimos 30 años, tomando como referencia las primeras UC que se instalaron en el territorio metropolitano en la década del setenta.
} 
Mendoza, A. - Procesos y lógicas de las urbanizaciones cerradas en áreas metropolitanas.
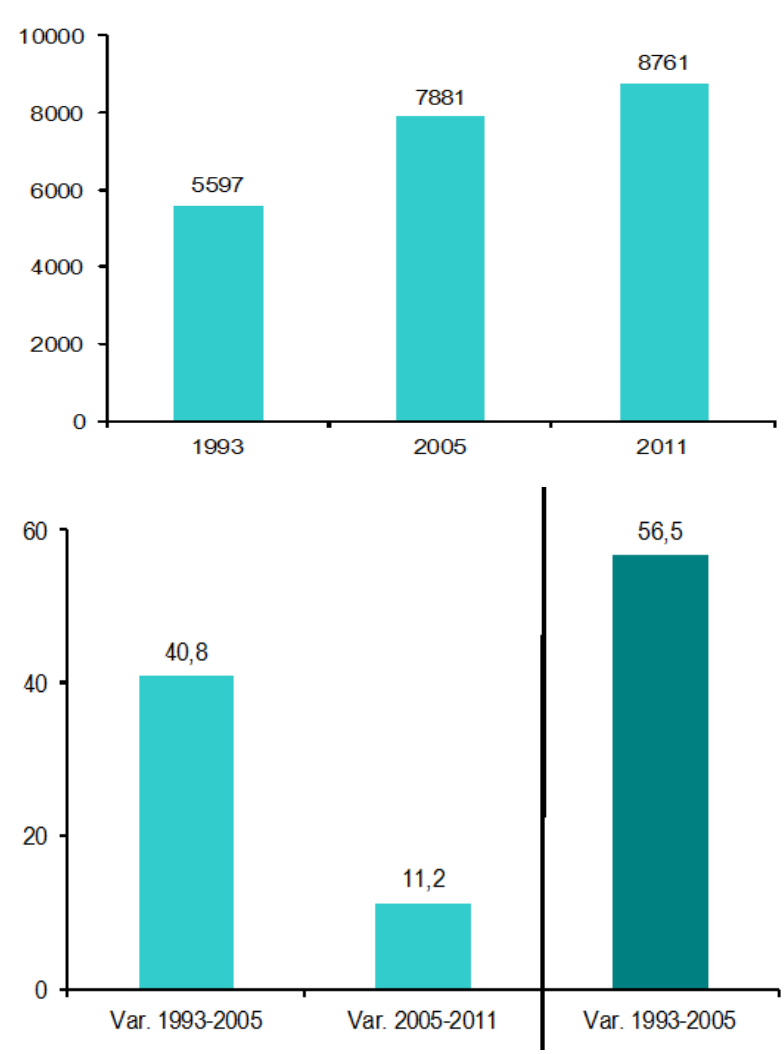

Figura 1. Población del Área Metropolitana de Bogotá (AMB) Totales absolutos y variaciones relativas interanuales. Años 1993-2005-2011. En miles de personas.

Fuente: Elaboración propia con base en información del Departamento Administrativo Nacional de Estadística (DANE).

la proliferación de desarrollos suburbanos de tipo residencial y recreativo que crean "paráfrasis de ciudad" en suelos naturales: "el country vacacional o de fin de semana motivó la construcción de zonas de vivienda 'no-urbana' de alto costo, tanto por el valor del terreno como de las construcciones, en la periferia bogotana" (Pergólis, 1998: 129).

En un contexto más reciente, también jugó un papel determinante en el proceso de expansión de la mancha urbana del AMB, la definición de límites urbanos inamovibles por parte del gobierno de Bogotá. Tales límites, que parten de la intención de implementar medidas tendientes a la densificación de la mancha urbana y de renovar urbanísticamente el centro de la ciudad, con la consecuente generación de "escasez de suelo urbanizable", estimularon a que los desarrollos urbanísticos que se iban a hacer en la ciudad se llevaran a cabo en los municipios metropolitanos.

Alfonso (2009) plantea que la instalación de las UC en los municipios del AMB se ha visto favorecida por la baja productividad rural y en la poca capacidad de recaudación tributaria de tales parcelas. Asimismo, al no ser presionados los propietarios de los suelos rurales para aumentar su capacidad de producción, estos prefieren alquilar dichas tierras y vivir del cobro de rentas o las venden para dar paso a nuevos proyectos residenciales. De esta manera y según el autor, aquellos municipios en donde se han instalado con mayor fuerza las UC fueron los mismos que se caracterizaron por el éxodo continuo de la población rural a los cascos urbanos y que contaban con una buena accesibilidad, entendida como la conectividad vial con Bogotá (ver tabla 1 y anexo 2$)^{8}$.

Resultado de sendos procesos, se configura una situación urbanística en la que prima la ocupación dispersa e indiscriminada con nuevas áreas urbanas, especialmente condominios y parcelaciones residenciales amplias las cuales aumentan los precios del suelo, generan una fuerte tendencia a la conurbación (consecuencia del descuido de los bordes urbanos), muestra un continuo suburbano con mosaicos de usos del suelo con extensiones industriales, residenciales y agrícolas poco integrados a la vialidad estructurante, nuevos centros poblados en las veredas y el derroche de suelos con la afectación sobre el componente medioambiental -pérdida de áreas de filtración, bosques y páramos junto a la alteración del paisaje natural- y la disminución de la capacidad agrícola del área rural.

Esta última particularidad define la fragmentación del territorio en la zona norte: en los municipios de Cajicá, Chía y Cota se están desarrollando de manera intensiva formas dispersas de ocupación del suelo con el incremento de la urbanización de suburbios carentes de espacio público

8 Para dar una idea de la magnitud de lo aquí apuntado, el autor señala que Chía presenta un consumo del suelo rural por UC cercano al 7\% mientras que otros municipios como Cajicá, Cogua y Sopó oscilan entre el $1 \%$ y el $6 \%$ (Alfonso, 2009). 
adecuado y acelerado fraccionamiento de las parcelas. Esto se ha constituido en un problema de base para la formulación de una agenda regional de trabajo (Alcaldía Mayor de Bogotá, 2000).

\section{Configuración urbana}

Según Mosquera y Aprile-Gniset (1984), la multiplicación de centralidades periféricas se reveló en el AMB con la diversificación y el aumento de las actividades socioproductivas desarrolladas entre la ciudad y su área de influencia, las cuales incluyeron: el aumento de las funciones e interrelacionamientos con los municipios; el posicionamiento de algunas localidades como ciudad dormitorio para los trabajadores de la urbe; el significativo crecimiento en el empleo local de los municipios -que aun así es insuficiente para absorber a la totalidad de mano de obra disponible- y por último, la híper-centralización de servicios comerciales y dotacionales en la ciudad de Bogotá.

De igual forma, la especialización funcional de los municipios del área metropolitana generó "una clara segregación espacial y una diversidad en los tipos arquitectónicos y habitacionales en los materiales y técnicas, lo que indica una fase de diversificación y especialización productiva, con numerosos papeles y actividades económicas, categorías socio-profesionales y niveles de ingreso dispares y contrastantes" (Mosquera y Aprile-Gniset, 1984: 15). Esto se verifica en el hecho de que "algunas familias adineradas se instalan en la periferia norte (Cota, Cajicá y Chía), donde buscan la calidad de vida que no pueden encontrar en una ciudad atestada, polucionada y que carece de espacios verdes" (Dureau, Barbary y Lulle,

Tabla 1. Conectividad en el Área Metropolitana de Bogotá (AMB). Principales rutas de conexión entre la ciudad de Bogotá y el área metropolitana.

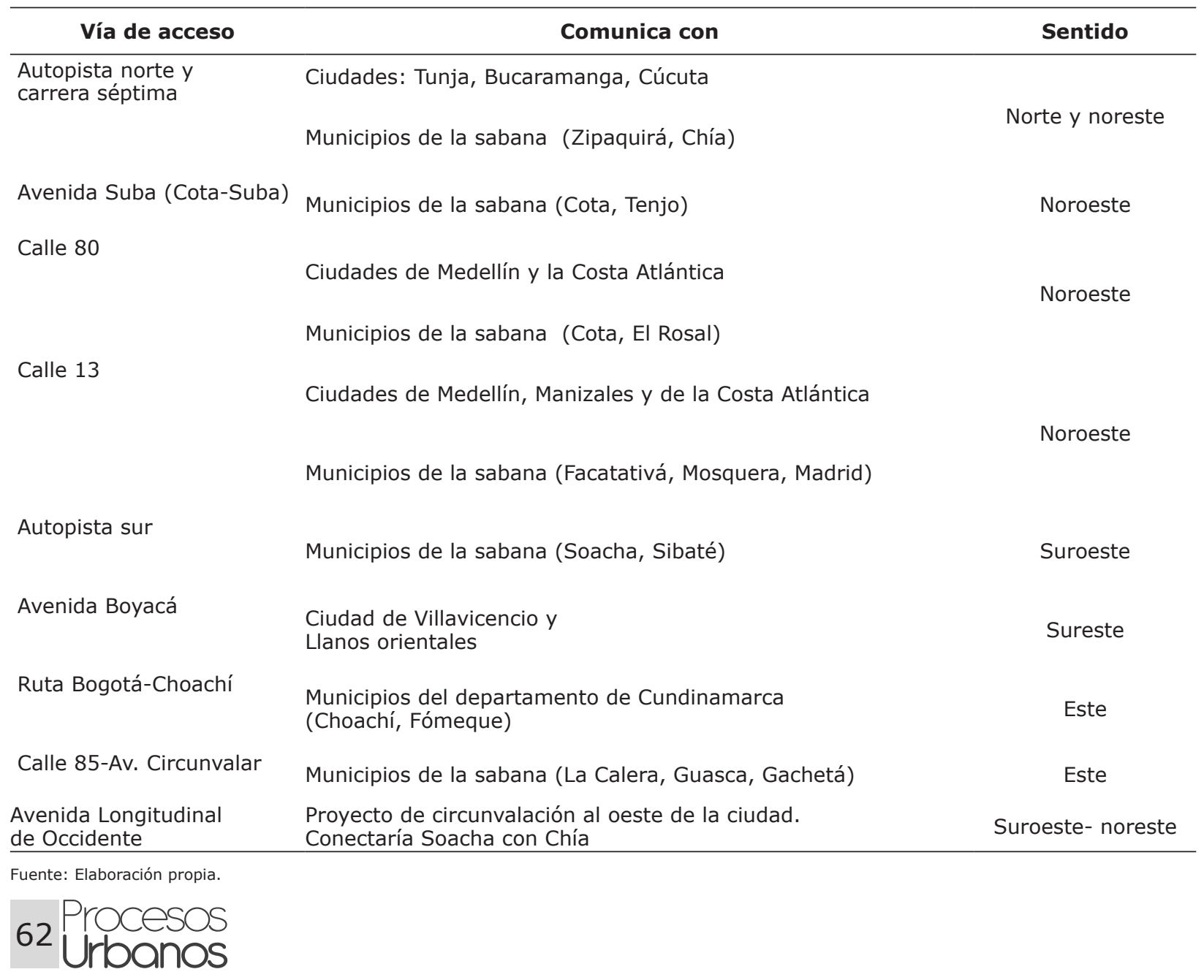


Mendoza, A. - Procesos y lógicas de las urbanizaciones cerradas en áreas metropolitanas.

2007: 173); mientras que en la región occidental -compuesta por los municipios de Mosquera, Facatativá, Madrid y el Rosalse dedica el territorio al desarrollo de actividades agroindustriales y de cultivos de flores. Por su parte, en los municipios del sur (Soacha y Sibaté), se evidencia la recepción de los contingentes migrantes nacionales pertenecientes a estratos socioeconómicos desfavorecidos ${ }^{9}$.

Abba (2010) señala que con la consolidación de la periferia urbana, gracias a la integración funcional, aparecen nuevos y múltiples nodos que ofrecen los mismos servicios que se pueden encontrar en el centro tradicional de la ciudad. Tales subcentros, ubicados en localizaciones estratégicas de consumo, se convierten en receptáculos de nuevas actividades siempre que cuenten con algunas ventajas comparativas: mano de obra barata, espacio físico para el desarrollo empresarial, disponibilidad de capital y de mercados, entre otras.

Esto ha comenzado a ocurrir en el caso del AMB en la última década, pues jalonado por la instalación de UC a lo largo y ancho del territorio, surge el emplazamiento de nodos comerciales siguiendo las principales autopistas de acceso a la ciudad central: en los municipios del norte con usos comerciales (centros comerciales), de ocio (parques temáticos y clubes deportivos) y usos institucionales (universidades y centros de atención en salud), mientras que en la salida occidental de la ciudad (sobre la autopista Medellín y calle 13), se consolida

9 Algunos rasgos que definen a los municipios localizados al norte de Bogotá, son: cualidades paisajísticas y ecológicas que han hecho que sean atractivos para el desarrollo de turismo de fin de semana o para la localización de vivienda campestre, buena infraestructura para la dotación de servicios públicos domiciliarios, así como la buena calidad en equipamientos y servicios públicos urbanos. Adicionalmente, cabe señalarse que los gobiernos locales de algunos municipios han promovido la instalación de población con un alto poder adquisitivo, ya sea a través de la permisibilidad en la construcción de viviendas campestres o de equipamientos comerciales de alto perfil (centros comerciales especializados, paseos gastronómicos, entre otros). En los municipios del occidente, juega un pape importante el impulso que desde tiempo atrás ha tenido el desarrollo de actividades industriales, agropecuarias y en menor medida de servicios financieros e inmobiliarios. Allí se encuentra que aquellos municipios que se encuentran más cercanos a Bogotá son más dinámicos, mientras que aquellos que se van alejando más de Bogotá predominan las actividades rurales y su actividad económica es menor. El desarrollo del eje occidental ha estado siempre vinculado con la opción de desarrollar el Macroproyecto Urbano Regional del Área de Influencia del Aeropuerto El Dorado (MURA) y todo un corredor logístico en los municipios adyacentes. Por último, en el caso del municipio de Soacha, al sur de la ciudad de Bogotá, este se ha convertido en polo receptor de contingentes de población desplazada de todo el país debido a su cercanía e interrelación con la capital (está conurbado completamente) y a que el perfil socioeconómico del mismo municipio es mucho menor al de los otros municipios de la sabana, siendo más accesible en los servicios urbanos. la instalación de parques industriales y empresariales (ver figura 2).

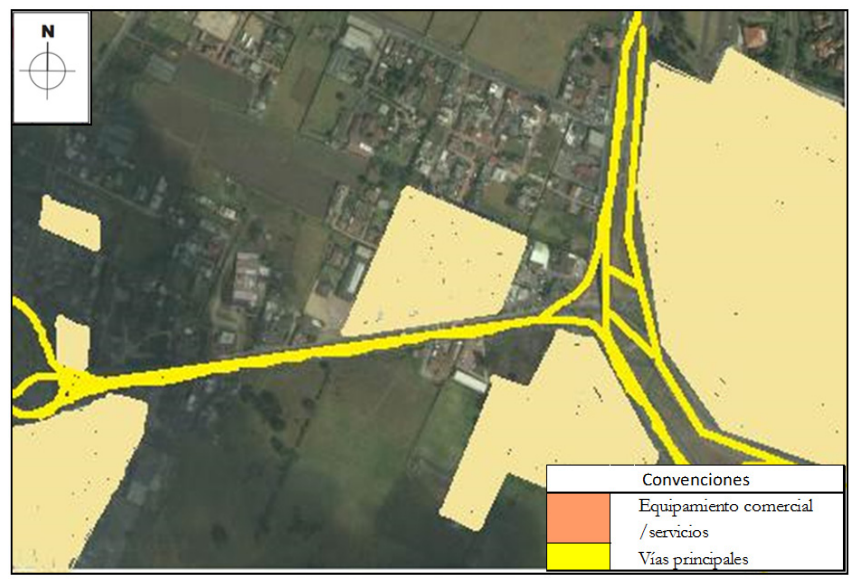

Figura 2. Foto satelital del nodo comercial en el municipio de Chía (Cundinamarca)

Fuente: Elaboración propia con base en Google Earth (2013).

A este panorama hay que agregar la marcada desarticulación política entre los mismos gobiernos locales -alcaldías municipales- y la escala intermedia de gobierno -Gobernación del departamento de Cundinamarca-, lo cual se puede constatar no sólo en la inaplicación de la Ley de Áreas Metropolitanas vigente, pues además existe una "falta de voluntad política" de los alcaldes municipales y distrital por concertar temas comunes de trabajo $^{10}$. De esta manera, si bien han sido claros los impactos que han tenido los procesos urbanos hasta aquí mencionados en la estructuración del área metropolitana de Bogotá, estos han quedado por fuera del análisis de los equipos técnicos de planeación municipal, pues: "el énfasis contemporáneo de la administración de la ciudad en temas como la cultura ciudadana, el espacio público o los sistemas de transporte, han acaparado la atención de los medios y los expertos, ya sean técnicos o académicos" (Salazar, 2004, $3)$.

10 Los gobiernos locales no quieren perder la autonomía que gozan ac tualmente pues la lógica operativa del gobierno de Bogotá, es la de anexar a tales municipios bajo la figura de "Localidad", tal como ocurrió con los municipios de Fontibón, Engativá, Usaquén, Usme, Bosa y Suba. No obstante es válido destacar que Bogotá se puede considerar como la única ciudad en el país que propendió por fortalecer la idea de ciudad-región. Algunos intentos hechos en este sentido fueron el diseño de un Modelo de Ordenamiento Territorial para la Región Capital (MOT), así como de una serie de proyectos de movilidad y transporte que fueron establecidos por los Planes de Ordenamiento Territorial. 
Bajo tal panorama, el AMB corre el riesgo de tener la misma suerte que otras metrópolis del mundo, en las que el dispositivo gestor dominante es la yuxtaposición de entidades administrativas distintas -de tipo municipal-, sin que se forme un gobierno metropolitano autónomo. Esto aumenta el riesgo de que las administraciones locales más pequeñas o débiles, sean absorbidas por las más grandes, generalmente la ciudad central de la aglomeración. Asimismo, este tipo de relación amenaza con producir efectos indeseables, como el crecimiento de los centros urbanos, la concentración y aumento de las áreas de pobreza, la ocupación y el deterioro de las zonas rurales, la destrucción del medio ambiente y la desaparición de la economía de base rural de esos municipios.

\section{ÁREA METROPOLITANA DE BUENOS AIRES (AMBA)}

El área metropolitana de Buenos Aires (AMBA en adelante) muestra una extensión sobre el territorio que rebasó los límites de la ciudad desde fines de la década de 1940, momento a partir del cual se reconoce censalmente la existencia de un área urbana mayor al de la ciudad de Buenos Aires, el Gran Buenos Aires, con la que constituyen una unidad funcional metropolitana (Ciudad Autónoma de Buenos Aires + Gran Buenos Aires). En la actualidad, el AMBA se entiende como la aglomeración urbana comprendida por la ciudad de Buenos Aires y 32 municipios pertenecientes a la provincia de Buenos Aires, de los cuales 25 están integrados físicamente a la ciudad, mientras que los otros 7 están parcialmente articulados (ver anexo 3).

\section{Crecimiento poblacional}

Dada la estabilización de las tasas de crecimiento poblacional de la ciudad de Buenos Aires, en parte explicada por la urbanización total de su suelo, la llegada de contingentes migrantes de distintas partes del país y de países limítrofes se dirigió a los municipios del Gran Buenos Aires. El resultado de tales dinámicas fue la acelerada extensión de la mancha urbana, alcanzando a integrar físicamente a municipios distantes, acompañado de un acelerado crecimiento poblacional.
Según los últimos censos de población, entre los años 1991 y 2001, la población del AMBA aumentó un 10,7\% (es decir, 1.169.217 de personas), mientras que entre 2001 y 2010 creció un 12,5\% (alcanzando a las 13.601 .547 personas en este último año). Tomando los años extremos, 1991 y 2010, se observa entonces que en las dos últimas décadas la población creció en total un $24,6 \%$. Este dato no es menor, pues reflejaría la continuidad del patrón expansivo del factor demográfico en la metrópoli (ver figura 3).

En lo que hace a las dinámicas poblacionales, Szajnberg y Cordara (2010) señalan que una de las transformaciones más importantes del AMBA fue el crecimiento de población de la segunda y tercera corona metropolitana, como consecuencia de la distribución desigual de la población en el territorio,
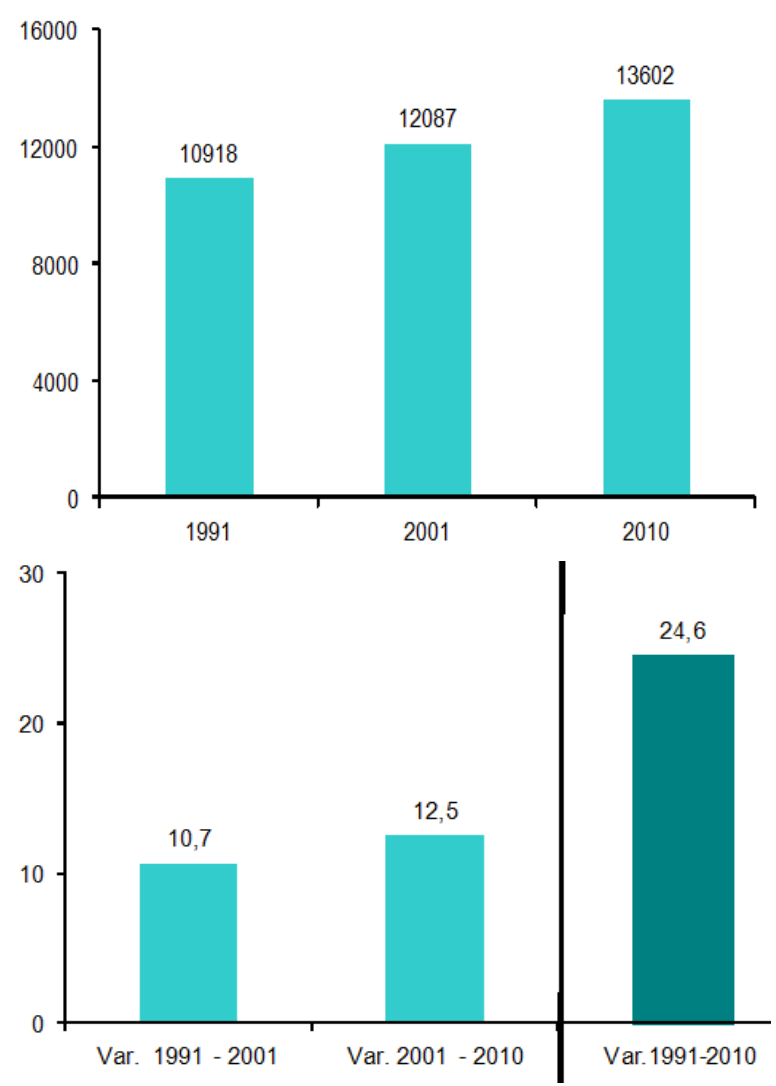

Figura 3. Población del área metropolitana de Buenos Aires (AMBA). Totales absolutos y variaciones relativas interanuales. Años 1991-2001-2010. En miles de personas.

Fuente: Elaboración propia con base en información del Instituto Nacional de Estadísticas y Censos (INDEC). 
Mendoza, A. - Procesos y lógicas de las urbanizaciones cerradas en áreas metropolitanas.

con lo cual, se podría hablar de un proceso de descentralización metropolitana con transferencia de población desde el centro y el primer anillo del conurbano, hacia la periferia. Al respecto, Pírez (2005) señala que en las décadas del noventa y de los años dos mil, el crecimiento poblacional de la ciudad de Buenos Aires experimentó un leve descenso, la primera corona incrementó un $3,4 \%$ su población, mientras que la segunda y tercera corona crecieron intensamente: $23,6 \%$ y $35,9 \%$ respectivamente.

\section{Instalación de UC}

Las sucesivas convulsiones económicas padecidas por el país -crisis de la deuda externa, contexto de hiperinflación y una acelerada caída de la inversión productiva interna y externa-, junto con el agravamiento de los indicadores socioeconómicos, fueron factores que ayudaron a disolver el imaginario integracionista existente en el contexto pre dictadura, por lo que, se hizo necesario refundar las bases sobre las cuales se asentaba la sociedad argentina. En este contexto, entró en vigencia la privatización acelerada de las diversas esferas sociales y el discurso neoliberal constituía ahora, el pilar sobre el cual descansaban todas las relaciones societales. Tales transformaciones dieron paso a las estrategias que privilegiaban el triunfo personal y la libre competencia como forma de construir nuevos mitos o valores que sirvieran para recomponer el tejido social perdido (Svampa, 2001).

Este contexto fue particularmente provechoso para los desarrolladores inmobiliarios, pues entraron a ejercer el rol estatal en lo que a vivienda se refiere, lo que desencadenó dos fenómenos contrarios: la emergencia de un mercado informal de lotes y la instalación de UC para las clases medias-altas en las periferias urbanas. Por ello, entre los años ochenta y noventa se consolidó un nuevo modelo de periferia urbana en la que primaba la intensiva construcción de UC. En este sentido, cabe destacarse que aun cuando la suburbanización de las clases medias y medias-altas en la Argentina se puede considerar tardía, si se la compara con las experiencias de otros países latinoamericanos, las características que asumió el fenómeno corresponde con los patrones de ocupación socioespacial y al modelo general de desarrollo económico que imperó en la época: crecimiento económico y estabilización monetaria, intensificación de la precarización y flexibilización laboral, junto a una alta concentración económica que disparó la desigualdad social (Torres, 2001).

El AMBA constituye en un importante caso de estudio para la temática aquí abordada, por las dimensiones que tomó el fenómeno, así como por la variedad en las tipologías presentes -usos de las viviendas privadas y la diversificación del paisaje que ha desarrollado a lo largo del tiempo-. De tal forma, la masificación que presentaron las UC en el AMBA fue tal, que de acuerdo con Svampa (2001) desde 1996 hasta el 2000 hubo una sobreoferta de proyectos (en total unos 230), mientras que en el año 2001 ya se habían instalado unos 434 emprendimientos en diferentes tipologías (252 barrios privados, 139 clubes de campo, 36 chacras y 7 ciudades satélite).

Del lado de la dimensión que tiene el fenómeno, Abba (2010) sostiene que alrededor de una tercera parte de la población habita en ellas, y que en el caso del AMBA, tales urbanizaciones ocupan una superficie mayor a la de la ciudad de Buenos Aires. Según datos de la Fundación Metropolitana (2010), las UC del Gran Buenos Aires ocupan una superficie de $360 \mathrm{~km}^{2}$ y en ellos viven alrededor de 250 mil personas, mientras que la ciudad de Buenos Aires ocupa apenas $200 \mathrm{~km}^{2}$ y contiene más de tres millones de habitantes. Esto nos estaría indicando la desigualdad en las condiciones de ocupación del suelo urbano y la débil regulación que han ejercido los gobiernos locales sobre el fenómeno urbanístico.

Esa metropolización difusa hace que se configuren distintos paisajes a lo largo de la extensión del área metropolitana, desde la forma más compacta en el centro de la ciudad núcleo, hasta "que el paisaje ingresa en una inter-fase de paulatina y constante urbanización difusa de escasa intensidad edilicia y con escasa o nula consolidación

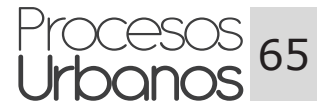


urbana que se expande sobre un área total de unos $14.000 \mathrm{~km}^{2}$, de los cuales se estima que solo unos $3.000 \mathrm{~km}^{2}$ son de suelo urbano real" (Szajnberg y Cordara, 2011: 17).

Ahora bien, en lo que refiere a su desarrollo, Svampa (2001) señala que las primeras construcciones de tipo cerrado que surgieron en el territorio metropolitano, se conformaron bajo la forma de loteos tradicionales que solo posteriormente se organizaron como entidades jurídicas, sociedades anónimas o cooperativas de propietarios. Es decir que en un primer momento, su uso era restringido a vivienda de fin de semana para la práctica de deportes selectos -principalmente ecuestres y golf- y para la intimidad familiar; motivo por el cual no estaban equipadas con la infraestructura necesaria para funcionar como residencias permanentes. A juicio de la autora, la inclusión de estos primeros modelos residenciales dentro de la oferta inmobiliaria de UC, plasmó las nuevas lógicas de ocupación del suelo que se instauraron a partir de la década de los setenta, dejando de ser un bien de lujo para convertirse en una necesidad básica de las familias.
Un segundo boom en el desarrollo de tales proyectos residenciales se dio gracias a la creciente y exitosa clase media-alta que estaba deseosa de afirmar su consagración social, a través de la adopción de un estilo de vida country. Dicha nueva élite, heredera de un estilo de vida más laxo y hedonista, pretendió trasladar todas las comodidades urbanas a sus residencias temporales en el campo. En ese contexto, el papel que jugaron la sensación de seguridad y el automóvil fue importante, pues encontraron una respuesta contundente en las nuevas viviendas, con seguridad privada y la conectividad efectiva a través de las grandes autopistas (ver figura 4 y anexo 4).

La situación económica del país también determinó comportamientos particulares para el caso argentino, pues una vez superada la crisis del año 2001, se consolidó en el mercado una nueva tipología dentro de las UC: los mega emprendimientos, denominados comercialmente "ciudad pueblo" o "pueblo privado". La zona norte del AMBA se convirtió así en el sector preferente

Tabla 2. Conectividad en el área metropolitana de Buenos Aires (AMBA). Principales rutas de conexión entre la ciudad de Buenos Aires y el área metropolitana.

\begin{tabular}{llc}
\hline \multicolumn{1}{c}{ Vía de acceso } & \multicolumn{1}{c}{ Comunica con } & Sentido \\
\hline Autopista Panamericana & Ciudades: Rosario, Córdoba y Río Cuarto & Noroeste \\
& Ramal Escobar (Ruta provincial 9) & Noroeste \\
& Ramal Pilar (Ruta provincial 8) & Noroeste \\
& Ramal Tigre & Norte-suroeste \\
Autopista Camino del Buen Ayre & Circunvalación que comunica la Panamericana con el Acceso & Oeste \\
Acceso oeste (Au. 7) & Oeste & Oeste \\
& Ciudades: San Luis y Mendoza & Sur-suroeste \\
Autopista Ricchieri & Municipios del interior de la provincia (Luján, San Andrés de Giles) & Sur-suroeste \\
Autopista Ezeiza-Cañuelas & Aeropuerto internacional Ezeiza & Sur-sureste \\
Autopista Buenos Aires - & Conecta con Cañuelas & Sur-sureste \\
Mar del Plata (Au. 2) & Chascomús y Mar del Plata &
\end{tabular}

Fuente: Elaboración propia. 
Mendoza, A. - Procesos y lógicas de las urbanizaciones cerradas en áreas metropolitanas.

en el que se concentró la instalación de tales proyectos $^{11}$.

Los mega emprendimientos cerrados surgieron con la intención de satisfacer la demanda existente de productos residenciales integrales que combinaran una diversidad de propuestas habitacionales y que contaran con una completa infraestructura de servicios, de manera que permitieran a sus residentes, concentrar las actividades cotidianas en un mismo lugar y no se necesitara salir de los muros de la UC. La consolidación de este formato habitacional dentro de las tipologías de UC existentes, permite reconocerles un carácter de ciudades satélite, en virtud de que son emprendimientos que cuentan con una cierta autonomía para su funcionamiento. Cabe destacarse que al mismo tiempo, este formato representa cambios en comparación con las tipologías tradicionales de UC, pues generan espacios abiertos de uso público.

Sin embargo, la multiplicación de estas ciudades satélites y en general de las UC, sin una adecuada intervención de la gestión urbanística, ofrece múltiples riesgos como lo son los graves conflictos ambientales y sociales, no solo con la contaminación de los recursos naturales, sino también con la intensificación de la polarización social y fragmentación administrativa. En este sentido, se evidencia que la instalación de tales emprendimientos sobre porciones del suelo ocupados previamente por sectores populares o dedicados a las actividades rurales, ha potenciado las distancias sociales entre los grupos y determinó una suerte de micro segregación residencial. A su vez, la intensiva mercantilización del suelo rural para el desarrollo de grandes proyectos urbanísticos residenciales y comerciales, ha tenido un impacto especulador directo sobre el valor del suelo, por lo que se ha encarecido considerablemente sin que las administraciones locales hayan obtenido beneficio de ello. Esto se puede entender si se considera la falta de reglamentaciones tributarias fuertes en algunos casos, y en otros porque desde las mismas dependencias

11 Allí la oferta disponible en el mercado inmobiliario de UC resulta variado en precios -según la zona, ubicación, superficie y etapa del proyecto- y tipologías -abarca desde lotes con vista al golf, al río o a la laguna, hasta condominios o complejos de oficinas-. encargadas de la gestión urbanística se ignoran las dinámicas aquí descritas ${ }^{12}$.

\section{Configuración urbana}

La primacía del AMBA radica no solo en la concentración de población, sino también en la jerarquía de los equipamientos y servicios con que cuenta y en su capacidad para atraer inversiones de capital. En tal sentido, Vidal-Koppman (2006) señala que el área metropolitana de Buenos Aires, dentro de la lógica de ciudades mundiales, logró atraer en mayor proporción funciones globales de servicios con las que consolidó una dinámica doble: se dio una concentración de funciones al tiempo que ocurría una dispersión urbana y poblacional importante.

El caso argentino ha sido abordado por Prévôt Schapira (2002), Torres (2001), Vidal-Koppman (2006), Szajnberg (2005) Szajnberg y Cordara (2010) y Vecslir (2011), los cuales coinciden en afirmar que las grandes intervenciones urbanísticas que trajo aparejada la instalación de UC en amplias porciones del suelo periférico de la ciudad de Buenos Aires, preferencialmente en la zona norte, resultó en la configuración de un nuevo paisaje urbano fragmentado, muy distante al del pueblo tradicional: "este proceso conllevó cambios notables en la trama urbana de la ciudad a partir de la expansión de nuevos ámbitos de comercialización de bienes y servicios como hipermercados, shoppings, multicines (...)" (Svampa, 2001, 52).

En este sentido, se puede señalar que una particularidad importante que presentó el AMBA dentro de su proceso de conformación, fue que junto con la instalación de UC a lo largo y ancho del territorio, se dio el emplazamiento de centralidades/enclaves/ nodos $^{13}$ comerciales y con actividades productivas siguiendo las principales autopistas de acceso a la ciudad de Buenos Aires (principalmente en la zona norte y

12 Entre los más importantes emprendimientos de este tipo de la zona norte del AMBA se pueden señalar: Nordelta, Ayres de Pilar, Pilará y Estancias de Pilar. Un análisis más detallado sobre este tema se puede encontrar en Vidal-Koppman (2006) y Mendoza (2014).

13 Aquí vale la pena señalarse que la formación de tales nodos no fue homogénea, por lo que se presentaron diferentes tipologías de agrupación: corredores comerciales y de servicios, enclavados sobre los accesos a la ciudad, o en forma de nodos comerciales, que aparecen gracias a la alta concentración de edificaciones y actividades de gran escala en puntos de máxima accesibilidad -enlaces viarios y/o accesos urbanos-. 
noroeste). A esto contribuyó la diversificación de los procesos de suburbanización y la modificación estructural en las condiciones locacionales que necesitaba el sector empresarial (Vecslir, 2011; Vidal-Koppman, 2006).

Estos polos constan de importantes centros de 'ocio y consumo', como lo son centros comerciales, supermercados, restaurantes y cines. Las nuevas centralidades/enclaves/ nodos de bienes y servicios, dirigidas preferencialmente a la población de niveles socioeconómicos altos y medios-altos, han ocasionado un "paulatino abandono"14 de las centralidades tradicionales de la ciudad consolidada, de manera que la jerarquía clásica de los lugares centrales es sustituida por un sistema de centros comerciales,

14 Se habla en términos relativos pues aquí se está indicando la conformación de nuevos subcentros metropolitanos que en algunos casos, resultan complementarios con la centralidad tradicional, pero que determinarían al mismo tiempo, la conformación de un nuevo tipo de suburbio, con formas de urbanización y suburbanización más dispersas. colonias y áreas especializadas (Abba, 2010; Vidal-Koppman, 2006; Vecslir, 2011; Szajnberg y Cordara, 2010) (ver figura 4).

Ahora bien, otros impactos que se pueden leer de las dinámicas urbanas hasta aquí expuestas son: crecientes problemas de transporte, falta dedotación deinfraestructura de servicios urbanos y públicos domiciliarios -dado el crecimiento poblacional en zonas sin dicha infraestructura-, derroche del suelo disponible con la consecuente expansión sin fronteras de la mancha urbana, además de los problemas de seguridad y salubridad como consecuencia de la fuerte contaminación de los recursos medioambientales.

Al igual que ocurrió en el área metropolitana de Bogotá, arriba descrita, la instalación de tales emprendimientos sobre porciones del suelo ocupados previamente por sectores populares o dedicados a las actividades

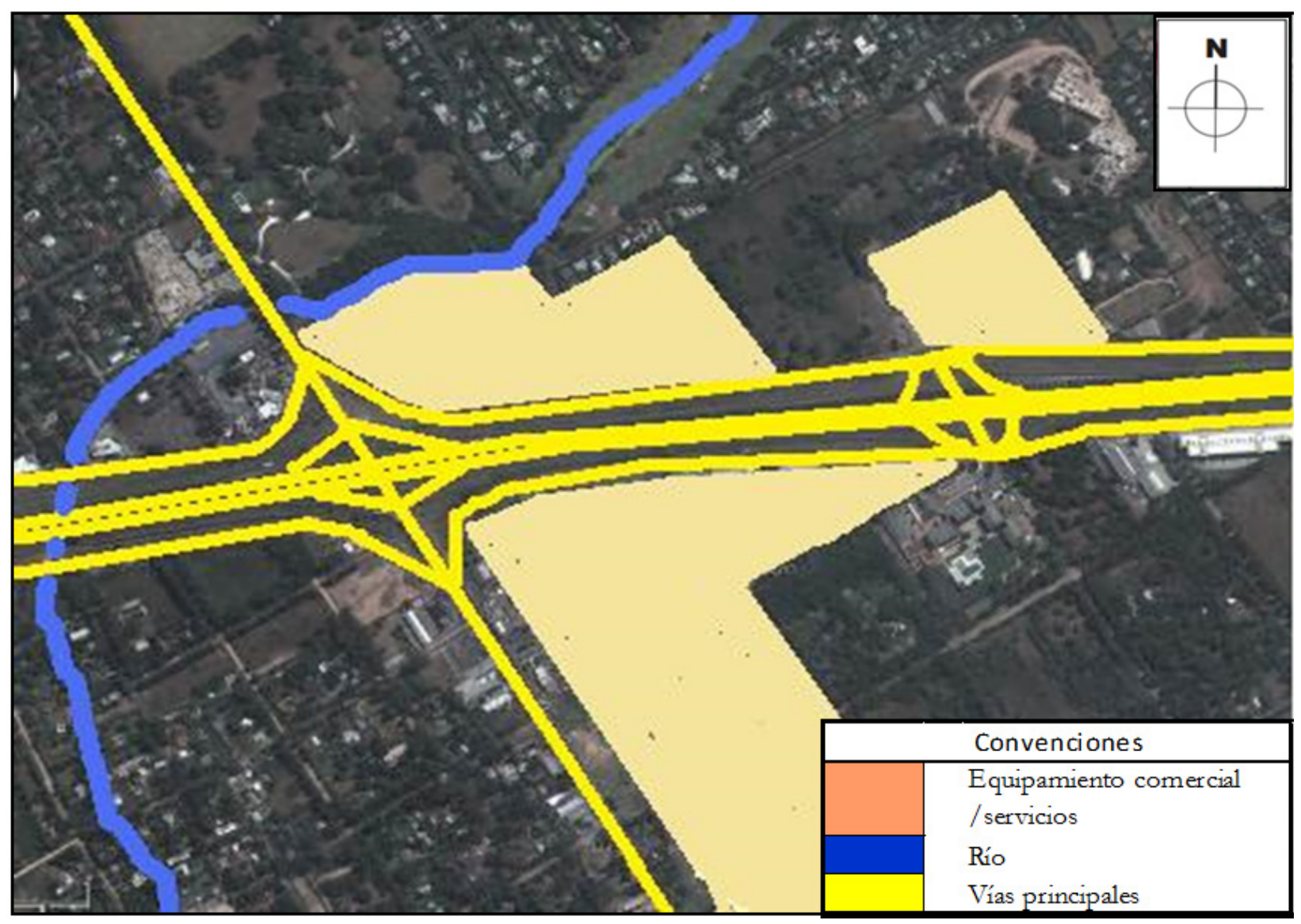

Figura 4. Fotografía satelital del nodo comercial del Kilómetro 50 de la autopista Panamericana en el AMBA. Fuente: Elaboración propia con base en Google Earth (2013). 
Mendoza, A. - Procesos y lógicas de las urbanizaciones cerradas en áreas metropolitanas.

rurales, potenció las distancias sociales entre los grupos y determinó una suerte de micro segregación residencial. Ello se evidenció en algunos lugares, en los que las UC parecen verdaderas fortalezas amuralladas incrustadas en barrios empobrecidos. A su vez, la intensiva mercantilización del suelo rural para el desarrollo de grandes proyectos urbanísticos residenciales y comerciales, tuvo un impacto especulador directo sobre el valor del suelo, por lo que se ha encarecido considerablemente sin que las administraciones locales hayan obtenido beneficio de ello.

\section{LECTURA COMPARADA}

La descripción hecha sobre el proceso de configuración de las áreas metropolitanas latinoamericanas en general, y las lógicas de ocupación del suelo basado en el producto inmobiliario de las UC en específico para Bogotá y Buenos Aires, permitió ver un conjunto de fenómenos polarizadores y agravantes que fueron comunes a las dos metrópolis:

\section{Crecimiento poblacional}

(a) Relación causal entre el intensivo crecimiento poblacional y la extensión descontrolada de la mancha urbana: en los periodos intercensales 1990-2010 la población del AMB creció un 56,5\% $y$ en el AMBA un respectivo $24,6 \%$. Ese crecimiento se hizo lento para las ciudades centrales, mientras que en los municipios metropolitanos tomaron dinamismo.

(b) Al ser las áreas metropolitanas principales de sus respectivos países se convirtieron en polo de atracción para las distintas corrientes migratorias nacionales; sin embargo, ahora los municipios metropolitanos son los receptores de la población migrante.

(c) La continuidad urbana es un hecho que se presenta en ambas metrópolis: en el AMBA la ciudad rebasó los límites desde fines de la década de 1940 -configurando el Gran Buenos Aires- y en el AMB recién hay integración física con el municipio de Soacha.

\section{Instalación de UC}

(a) Instalación intensiva de desarrollos suburbanos de tipo residencial (UC) y recreativo en todo el territorio metropolitano a partir de las reformas político-económicas y transformaciones sociales de los años ochenta.

(b) El estilo de vida country y las UC como fenómeno urbanístico es compartido en ambas metrópolis, sin embargo tomó unos rasgos diferenciales: en el caso argentino, tiene unas dimensiones (extensión territorial, cantidad y tipologías presentes) considerables, mientras para el AMB no existen datos oficiales ni académicos sobre su dimensión e impactos en el territorio (hasta el momento se han hecho aproximaciones académicas aisladas). En el mismo sentido, mientras que en el AMB se habla de la instalación de un tipo de UC dominante condominios campestres-, en el AMBA existe una amplia variedad en la tipología de UC instaladas (country club, barrio cerrado, mega emprendimientos), lo cual ha tendido a complejizar su tratamiento desde la gestión urbanística de los gobiernos locales. Además, y en el caso argentino el fenómeno urbanístico se ha visto determinado por las sucesivas convulsiones económicas padecidas por el país, mientras que en Colombia se ha mantenido relativamente estable.

(c) Conformación de un sistema de vialidad radial con centro en la ciudad capital/centro, en el cual se evidencia la dependencia al automóvil privado y a las autopistas que conectan los municipios con la ciudad. La buena accesibilidad determinó la localización de muchas UC.

(d) Acelerado fraccionamiento de las parcelas y efecto especulativo en los precios del suelo rural sin que las administraciones locales se vean favorecidas de estas dinámicas (debido en parte a la baja capacidad de recaudación tributaria de las autoridades locales).

(e) Fragmentación del territorio: en el marco de la suburbanización que incentivan las UC, se da un continuo con mosaicos de usos del suelo con extensiones industriales, residenciales y agrícolas poco integrados a la vialidad estructurante, nuevos centros poblados en las áreas rurales -carentes 
de espacio público adecuado, falta de dotación de infraestructura de servicios urbanos y públicos domiciliarios- y el derroche de suelos con la afectación sobre el componente medioambiental -pérdida de áreas de filtración, bosques y páramos junto a la alteración del paisaje natural- y la disminución de la capacidad agrícola del área rural. A estos se suman problemas como los crecientes problemas de transporte, de seguridad y de salubridad como consecuencia de la fuerte contaminación de los recursos medioambientales.

(f) Potencialización de los conflictos sociales reflejados en la polarización social o segregación residencial a escala micro.

\section{Configuración urbana}

(a) Influencia de la ciudad central sobre los municipios que la rodean: concentración de los servicios de mayor jerarquía en la ciudad capital/centro. Esto incluye servicios asistenciales, financieros, administrativos, fuentes de empleo, con el consecuente reforzamiento de la dependencia de los municipios metropolitanos como "ciudades dormitorio".

(b) Formación de nodos especializados (comercio, usos institucionales, parques empresariales-industriales) en suelo suburbano de la metrópolis siguiendo la red vial principal. Estos nodos ofrecen los mismos servicios que se pueden encontrar en el centro tradicional de la ciudad, lo cual representaría un paulatino abandono de las centralidades tradicionales de la ciudad consolidada. Esa multicentralidad -que se podría entender como la diversificación y aumento de las actividades socio-productivas desarrolladas entre la ciudad y su área de influencia- ofrece mayor variedad en el caso argentino que en el colombiano.

(c) Desarticulación entre las distintas jurisdicciones en una escala metropolitana (gobiernos municipales y de nivel intermedio -departamental y/o provincial), que a la postre ha producido unos vacíos legales y unas situaciones de excepcionalidad que se hicieron comunes a ambas metrópolis. El reconocimiento funcional, mas no jurídico de las áreas metropolitanas, hace pensar que su situación no se modificará en el corto plazo si no se adoptan las medidas de concertación que resulten pertinentes.

(d) Complejización en la administración y manejo integral de los recursos naturales regionales (principalmente aire, agua y suelo) sin mencionar la intensificación de la conurbación como consecuencia del descuido de los bordes urbanos (aunque en ambas metrópolis ya se evidencia este fenómeno). (e) Dificultad para la prestación de servicios públicos domiciliarios y urbanos en la escala metropolitana que se hace necesaria para su adecuada gestión.

En cuanto a los procesos que fueron específicos a cada área metropolitana, se pudo encontrar lo siguiente:

\section{Instalación de UC}

(a) la suburbanización e instalación de UC está "explicada" en Bogotá por la baja productividad rural y la impacta decisiones políticas como la definición de límites urbanos inamovibles por parte del gobierno de Bogotá. En Buenos Aires se ha dado por una atracción preferencial de funciones globales de servicios en mayor proporción que otras ciudades latinoamericanas.

(b) En el AMB la instalación de las primeras UC se dio de forma tardía (década de los setenta), mientras que en el AMBA las primeras UC se instalaron con fines recreativos desde la década de los treinta -no como residencias permanentes-. Cabe recordarse que en el caso argentino, un factor explicativo de la instalación de UC es la desaparición del imaginario integracionista existente en el contexto pre dictadura; en ese sentido, aunque la suburbanización de las clases medias y medias-altas en la Argentina se puede considerar tardío, si se la compara con las experiencias de otros países latinoamericanos; las características que asumió el fenómeno corresponde con los patrones de ocupación socioespacial y al modelo general de desarrollo económico que imperó en la época.

\section{Configuración urbana}

(a) La definición de centros subregionales y de una especialización funcional (de tipo norte, occidente, sur) es más clara en Bogotá, mientras que en Buenos 
Mendoza, A. - Procesos y lógicas de las urbanizaciones cerradas en áreas metropolitanas.

Aires parece que la metrópolis comparte jerarquía funcional con la capital provincial (ciudad de La Plata), dada su proximidad (aproximadamente 50 kilómetros), aunque en esta segunda también se evidencia la especialización funcional: la zona norte del AMBA se convirtió en el sector preferente en el que se concentró la instalación de UC y de parques empresariales, mientras el occidente se ofrecía para la clase mediamedia baja.

(b) en el AMBA existe el potencial problema de una fragmentación administrativa y gobernabilidad como consecuencia de las nuevas UC -formato mega emprendimientosque dada su dimensión, podría solicitar ante las autoridades nacionales funcionar como un municipio aparte (como ha pasado en Beverly Hills).

(c) La jerarquía de los equipamientos y servicios con que cuenta y en su capacidad para atraer inversiones de capital indicaría que el área metropolitana de Buenos Aires, dentro de la lógica de ciudades mundiales, logró atraer funciones globales de servicios en mayor proporción que la metrópolis bogotana.

\section{CONCLUSIONES}

Como se pudo evidenciar del apartado anterior, son más las convergencias entre las dos áreas metropolitanas frente al mismo fenómeno urbanístico, que las divergencias. Esto estaría indicando que más allá de las particularidades que se señalan, se evidencia la consolidación de características comunes que inciden en la configuración de las áreas metropolitanas de Bogotá y Buenos Aires, por lo que se puede pensar que las administraciones locales de los territorios enfrentan retos comunes en cuanto a la gestión urbanística. Por esto, para terminar, se ofrecen algunas reflexiones finales $y$ recomendaciones focalizadas en aquellos puntos que se detectaron comunes y más complejos para las dos áreas metropolitanas y que se ofrecen como los retos de la metrópolis en el actual paisaje urbano:

Una primera medida que se considera general y útil para enfrentar muchos retos de la actual metrópolis -como el tema de transporte, seguridad y administración de los recursos naturales y servicios públicos-, es que se hace necesario que los gobiernos locales desarrollen sus agendas propias en términos de concertación regional, a través de la celebración de convenios sobre diferentes temas de interés común o estratégico. En este sentido, la gestión metropolitana debería entenderse como la interactuación entre las distintas partes de la metrópolis y la puesta en marcha de acciones en temas que resulten estratégicos y que involucren a todas las partes por igual. Una gestión de ese tipo, por unidades funcionales de planeación, debe velar entonces por conseguir una fluida relación con las escalas superiores del gobierno nivel departamental/provincial y nacional-, al tiempo que en el plano local realice la gestión urbanística de manera coordinada y actualizada.

Algunos temas a tratar en esta escala son: control a la continuidad urbana (consolidación y densificación del territorio propendiendo evitar la continua suburbanización en nuevos suelos); formulación de un plan de ordenamiento territorial metropolitano que considere las UC existentes y las medidas adecuadas para frenar su expansión indiscriminada y poner control al efecto especulativo en los precios del suelo rural por parte de las administraciones locales. Adicionalmente, dichos espacios deben abrir campo para la generación de nuevas asociaciones que incluyan a los tres actores principales en la construcción de la ciudad, es decir al Estado, la empresa privada y la sociedad civil.

Por su parte, como forma de menguar la fragmentación urbana y social que se hace presente en las dos áreas metropolitanas, resulta necesario implementar esquemas que fomenten la presencia de factores urbanos de progreso social, como son la mayor mixtura de usos del suelo con control y la consolidación de equipamientos e infraestructura urbana que propicien dicha integración; el control de los procesos de expulsión de población y fortalecimiento del componente de espacio público en zonas residenciales, como elemento ordenador de la ciudad y factor de redistribución e integración social; al tiempo que se

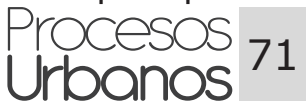




\section{Procesos Urbanos N³ Enero - Diciembre; 2016}

desarrollen programas para contrarrestar la inseguridad y la violencia urbana (tradicionalmente vinculadas a los problemas de segregación y exclusión poblacional).

Relacionado con el anterior aspecto, se encuentra la necesidad de fortalecer las centralidades metropolitanas para dinamizar las economías de los municipios metropolitanos, para evitar que la población tenga que recorrer grandes distancias hasta su lugar de trabajo/estudio y pueda tener una vida independiente de la ciudad central al tiempo que esos se conviertan en puntos de integración de la comunidad que facilite el acceso a bienes y servicios de distinto tipo. Esto implicaría además, la necesidad de revisar las directrices con las cuales se hace inversión en materia de vías, dando prioridad a las vías de segundo y tercer orden (de tipo inter e intra municipal); dejando de priorizar las vías que conectan con la ciudad central.

Finalmente, la organización y consolidación de la información concerniente a las UC instaladas en ambas metrópolis, también se constituye en una herramienta de suma importancia para las administraciones locales, pues su ausencia o parcialidad explica las trabas existentes para la definición de políticas que las regulen de manera efectiva o que permitan que los municipios se vean económicamente beneficiados con su instalación en los territorios. Esto quiere decir, definir hasta dónde se van a intensificar, en qué sectores serán permitidas, qué cualidades particulares deben tener los proyectos de esta naturaleza para que no irrumpan con el equilibrio pretendido y de acuerdo con la disponibilidad de suelo no construido y características del ya urbanizado, categorizar la estructura de movilidad, la capacidad de los servicios públicos urbanos y domiciliarios así como la agenda de negociación de los municipios con los actores inmobiliarios privados en el desarrollo de futuros proyectos de vivienda social (estableciendo en este sentido, la carga de responsabilidad social que debe tener cada UC para con el desarrollo de la comunidad).

\section{REFERENCIAS}

Abba, A. (2010). Metrópolis Argentinas. Agenda política, institucionalidad y gestión de las aglomeraciones urbanas interjurisdiccionales - 1a ed. - Martínez. Buenos Aires, Argentina: Café de las Ciudades. 176 p.

Alcaldía mayor de Bogotá (2000). Aproximación a las directrices de ordenamiento territorial para Bogotá y la región. Bogotá, Colombia: Convenio Corporación Andina de FomentoDepartamento Administrativo de Planeación Distrital- Centro de Estudios sobre Desarrollo Económico CEDE de la Universidad de los Andes.

Alcaldía municipal de Chía (2005). Revisión Plan de Ordenamiento Territorial del municipio de Chía. Chía, Colombia: SE.

Alfonso, O (2009). Profundización de las relaciones de metropolización de Bogotá con la Sabana, En VIII Seminario de Investigación Urbana y Regional. Bogotá DC, Colombia: Universidad Nacional de Colombia-IEU-ACIUR-CIDER.

Atlas de Buenos Aaires (2016). Contenido: Urbanización. (En línea). (Consultado el 10 de febrero de 2016). Disponible en: http://www.atlasdebuenosaires.gov.ar/aaba/index. php?option=com_ent\&task=view\&id $=27 \&$ Itemid $=23 \&$ lang $=$ es

Bermúdez, O. y Carvajal, N. (2004). La dimensión regional en los planes de ordenamiento territorial del área metropolitana de Bogotá en Revista Perspectiva Geográfica de la Universidad Pedagógica y Tecnológica de Colombia (UPTC). 11 (2005): 21-56. 
Mendoza, A. - Procesos y lógicas de las urbanizaciones cerradas en áreas metropolitanas.

Borsdorf, A. (2003). Cómo modelar el desarrollo y la dinámica de la ciudad Latinoamericana, en EURE, 29 (086) Santiago de Chile: Pontificia Universidad Católica de Chile.

Buzai, G. (2003). Mapas Sociales Urbanos. Buenos Aires: Lugar editorial.

Carballo, C. y Chevalier, J. (2005). Los espacios cerrados residenciales: en busca del entre-sí; estudio comparativo entre el norte y el sur del continente americano, en Revista Scripta Nova. Vol. IX (194). Barcelona: Universidad de Barcelona.

Correa, G. y Rozas, P. (2006). Desarrollo urbano e inversiones en infraestructura: elementos para la toma de decisiones. Santiago de Chile: CEPAL - División de recursos naturales e infraestructura. Disponible en: http://www.eclac.org/publicaciones/xml/8/25658/lcl2522e. pdf.

Delaunay, D. y DUREAU, F. (2004). Componentes sociales y espaciales de la movilidad residencial en Bogotá en Revista Estudios Demográficos y Urbanos (055): 77-113.

Departamento administrativo nacional de estadística -DANE- (2015). Contenido: Resultados del Censo Nacional 2005. (En línea). (Consultado el 01 de marzo de 2016). Disponible en: http://www.dane.gov.co/\#twoj_fragment1-4.

Dureau, F. et Al (2000). Metrópolis en movimiento. Una comparación internacional. Bogotá D.C.: IRDCIDS- Ed. Alfaomega.

Dureau, F., Barbary, O. y Lulle, T (2007). Capítulo Tercero: Dinámicas metropolitanas de poblamiento y segregación. En: INSTITUT DE RECHERCHE POUR LE DEVELOPPEMENT (IRD), INSTITUT FRANCAIS D 'ÉTUDES ANDINES (IFEA) y UNIVERSIDAD EXTERNADO DE COLOMBIA. Ciudades y Sociedades en mutación. Lecturas cruzadas sobre Colombia. Bogotá, Colombia.

Dureau, F. y Gouëset, V. (2007). Introducción General. En: INSTITUT DE RECHERCHE POUR LE DEVELOPPEMENT (IRD), INSTITUT FRANCAIS D 'ÉTUDES ANDINES (IFEA) y UNIVERSIDAD EXTERNADO DE COLOMBIA. Ciudades y Sociedades en mutación. Lecturas cruzadas sobre Colombia. Bogotá, Colombia.

Fundación metropolitana (2010). Contenido: Informe digital metropolitano número 70. (En línea). (Consultado el 01 de abril de 2015). Disponible en: http://www.forometropolitano. org.ar/wp-content/uploads/2012/05/Barrios-cerrados-ocupan-m\%C3\%A1s-sperficie-queCapital-Federal.pdf

Google earth. (En línea). (Consultado el 10 de abril de 2015).

Guerrero, R. (2006). <Nosotros y los otros>: Segregación urbana y significados de la inseguridad en Santiago de Chile, en Hiernaux, D. Lindon, A y Aguilar, M (coord) Lugares e imaginarios en la metrópolis. Madrid: Anthropos, 107-118.

Instituto nacional de estadísticas y censos -INDEC- (2015). Contenido: Resultados del Censo Nacional 2010. (En línea). (Consultado el 01 de marzo de 2016). Disponible en: http://www. censo2010.indec.gov.ar/.

Janoschka, M. (2002). El nuevo modelo de la ciudad latinoamericana: fragmentación y privatización, en EURE, 28 (085), 5-20. Santiago de Chile: Pontificia Universidad Católica de Chile. 


\section{Procesos Urbanos Nº 3 Enero - Diciembre; 2016}

Jaramillo, S. (1993). Urbanización Latinoamericana. Nuevas perspectivas. Bogotá D.C.: Ed. Escala.

(1999). El papel del mercado del suelo en la configuración de algunos rasgos socio-espaciales de las ciudades latinoamericanas, en Revista Territorios, vol. 2 (01), 107129. Bogotá D.C.: Universidad del Rosario.

Kralich, S. (2012). Sobre aglomerados en expansión: algunas precisiones conceptuales y su aplicación en el caso Buenos Aires. En: AINSTEIN, Luis (coordinador). Estructura urbana, institucionalidad y sustentabilidad de ciudades metropolitanas y regiones difusas. Miradas comparadas sobre Buenos Aires, Londres, Los Ángeles, París, Tokio, y Toronto. Buenos Aires, Argentina.

Lancioni, A. et al (2012). Expansión urbana en municipios bonaerenses: alcances y vínculos con las políticas de tierra y vivienda, en VII Congreso de Medio Ambiente AUGM. Disponible en: http://www.congresos.unlp.edu.ar/index.php/CCMA/7CCMA/paper/viewFile/996/253.

Mendoza, A. (2014). Gestión urbanística e institucionalidad en metrópolis de América del Sur. Munich, Alemania: Grin Verlag.

Mesa-Lago, C. (2002). Parte I. Introducción: Breve revisión del estado de las disciplinas de desarrollo económico de América Latina y los sistemas económicos comparados. En: MESALAGO, C. Buscando un modelo económico para América Latina ¿Mercado, socialista o mixto? Chile, Cuba y Costa Rica. Caracas, Venezuela.

Mosquera, G. y Aprile-Gniset, J (1984). Clases, segregación y barrios. Cali, Colombia: Editorial Universidad del Valle.

Pergólis, J. (1998). Bogotá fragmentada: Cultura y espacio urbano a fines del siglo XX. Bogotá, Colombia: Ed. Tercer Milenio - Universidad Piloto de Colombia.

Prévôt Schapira, M. (2002). Buenos Aires en los años '90: metropolización y desigualdades. Revista Eure vol. XXVIII (85): 31-50.

Salazar, O. (2004). Historia de la vida de la vivienda. Formas de vidas urbanas y significados del espacio domésticos en Bogotá. Tesis de grado para optar al título de magister en Antropología. Bogotá D.C.: Universidad de los Andes.

Svampa, M. (2001). Los que ganaron. La vida en los countries y barrios privados. Buenos Aires, Argentina: Ed. Biblos.

Szajnberg, D. (2005). La suburbanización. Buenos Aires, Argentina: Ediciones FADU. 2005.

Szajnberg, D. y Cordara C. (2010). Balance de las estrategias de intervención urbanística en los albores del siglo XXI en Revista Scripta Nova. vol XIV, número 331 (24).

(2011). Territorios desbordados y reactivación del debate sobre las políticas de ordenamiento territorial. Buenos Aires: SE.

Thuillier, G. (2005). El impacto socio-espacial de las urbanizaciones cerradas: El caso de la región metropolitana de Buenos Aires en EURE, año/vol. XXXI, no. 093. Santiago de Chile: Pontificia Universidad Católica de Chile. pp 5-20. 
Mendoza, A. - Procesos y lógicas de las urbanizaciones cerradas en áreas metropolitanas.

Torres, H. (2001). Cambios socioterritoriales en Buenos Aires durante la década de 1990. En Revista EURE, Vol. 27 (80).

Vecslir, L. (2011). Nuevas centralidades del ocio y el consumo. Ámbitos, modalidades e instrumentos de regulación de las grandes superficies comerciales en la región metropolitana de Buenos Aires. Revista Iberoamericana de Urbanismo (5): 31-44.

Vidal-Koppman, S (2006). La articulación global-local o cuando los actores privados construyen una nueva ciudad. Revista Scripta Nova Vol. X, Núm. 218 (39). Agosto 2006.

\section{ANEXOS}

Anexo 1. Área metropolitana de Bogotá y los anillos de municipios que la componen.

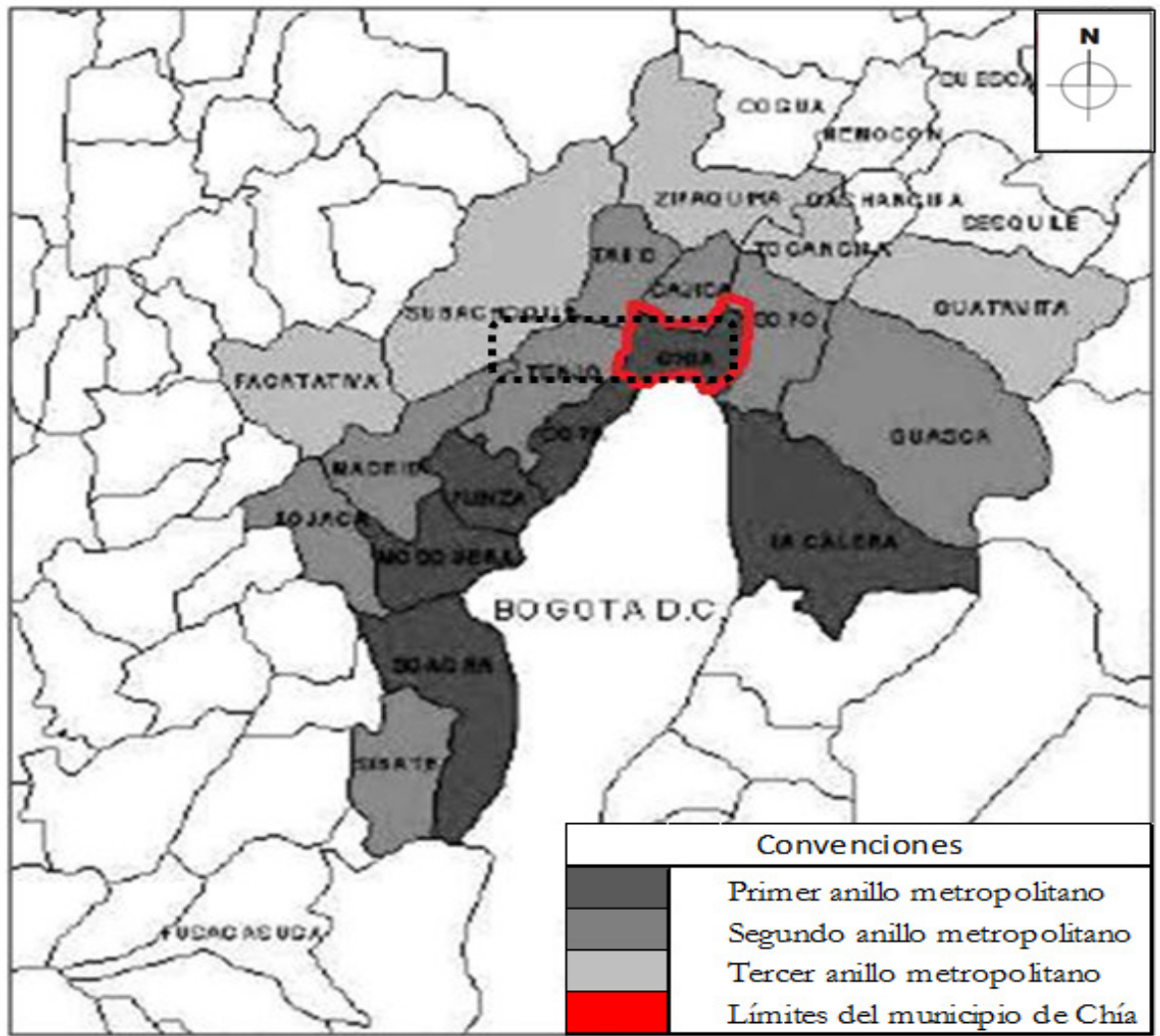

Fuente: Elaboración propia a partir de Bermúdez y Carvajal (2005). 
Procesos Urbanos N³ Enero - Diciembre; 2016

Anexo 2. Conectividad en el área metropolitana de Bogotá.

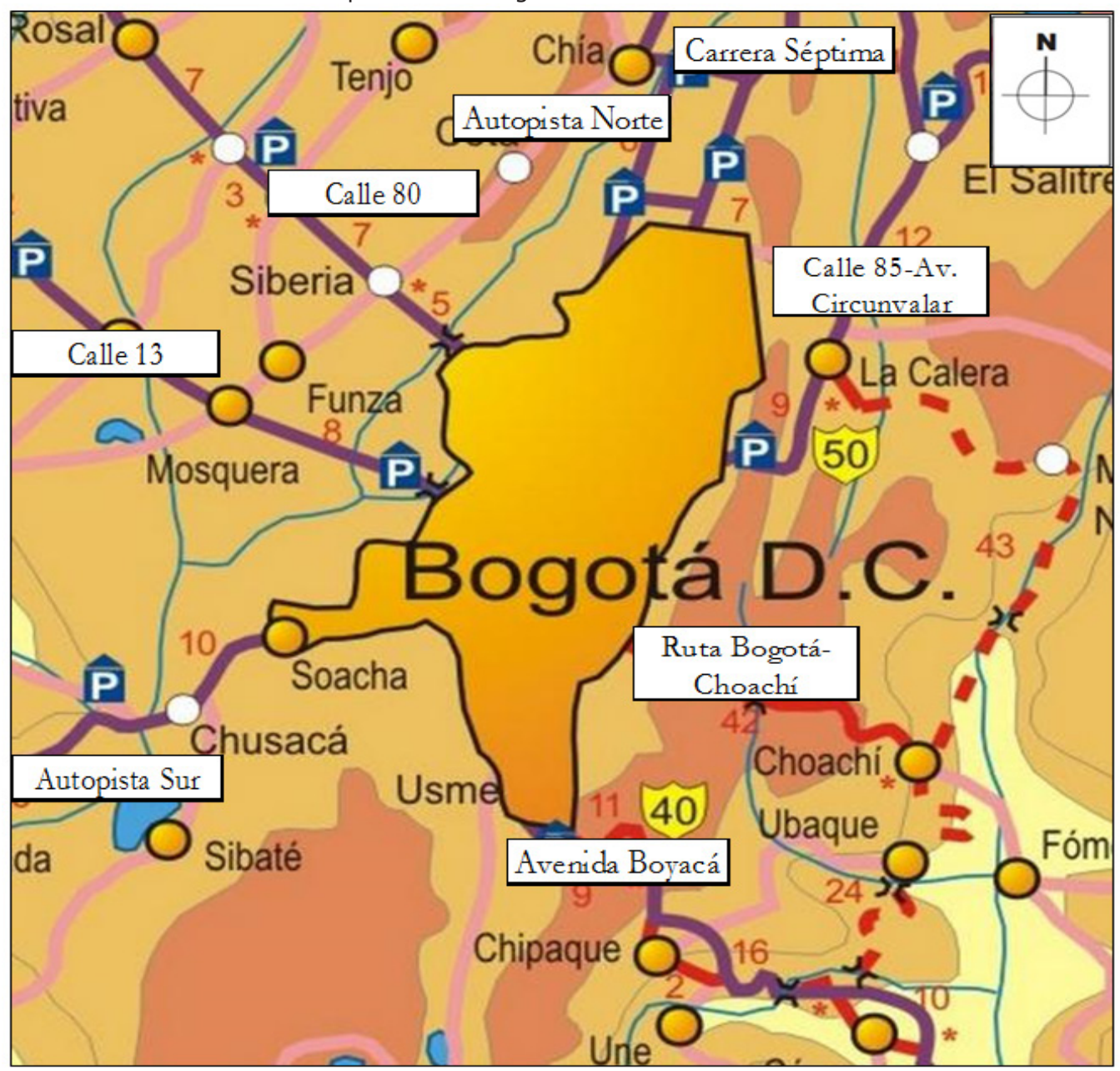

Fuente: Elaboración propia a partir de Zonu.com 
Mendoza, A. - Peocesos y lógiscas de las urbanizaciones cerradas en áreas metropolitanas

Anexo 3. Área metropolitana de Buenos Aires y los anillos de municipios que la componen

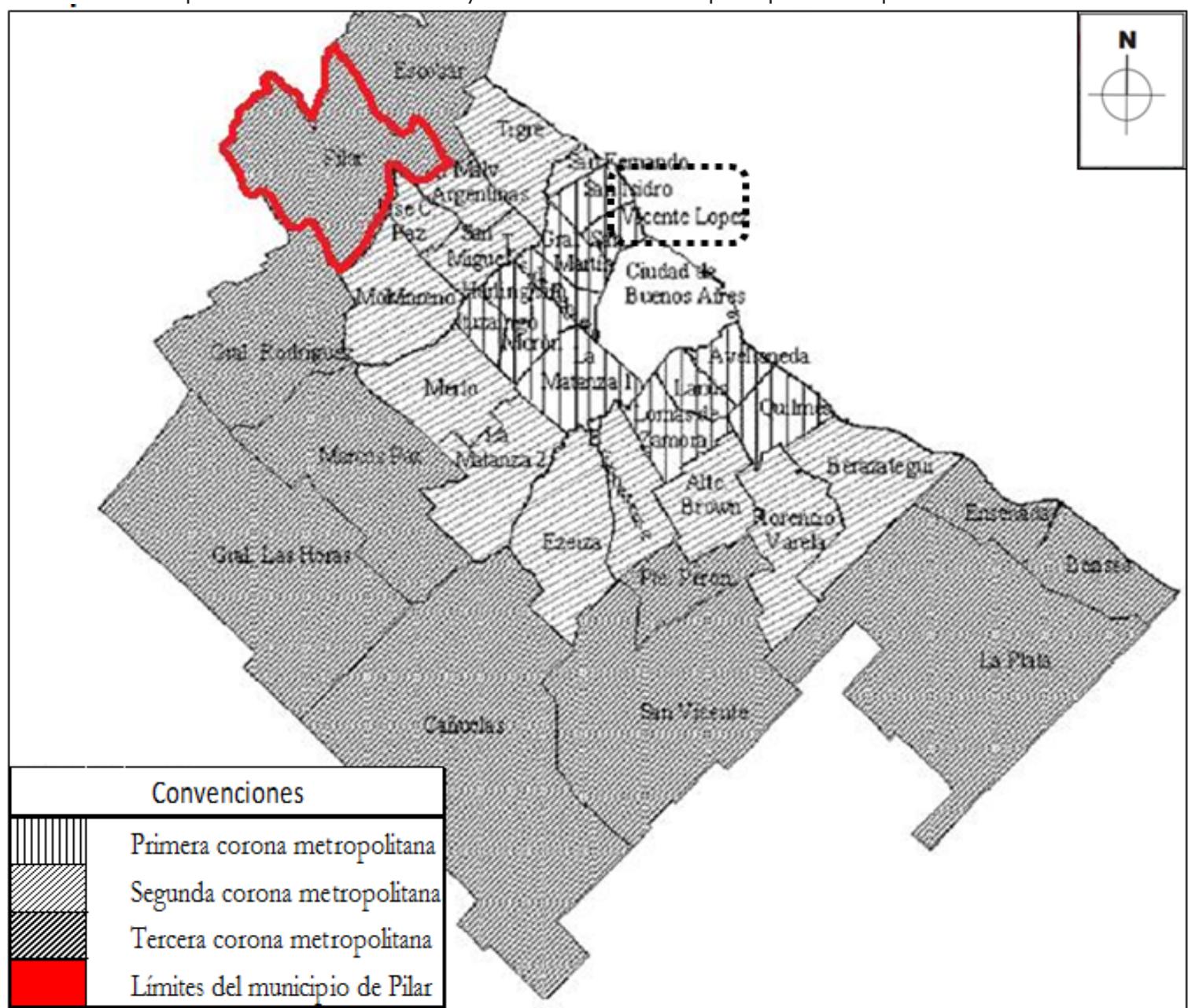

Fuente: Elaboración propia a partir de Kralich (2012). 


\section{Procesos Urbanos N³ Enero - Diciembre; 2016}

Anexo 4. Conectividad en el área metropolitana de Buenos Aires.

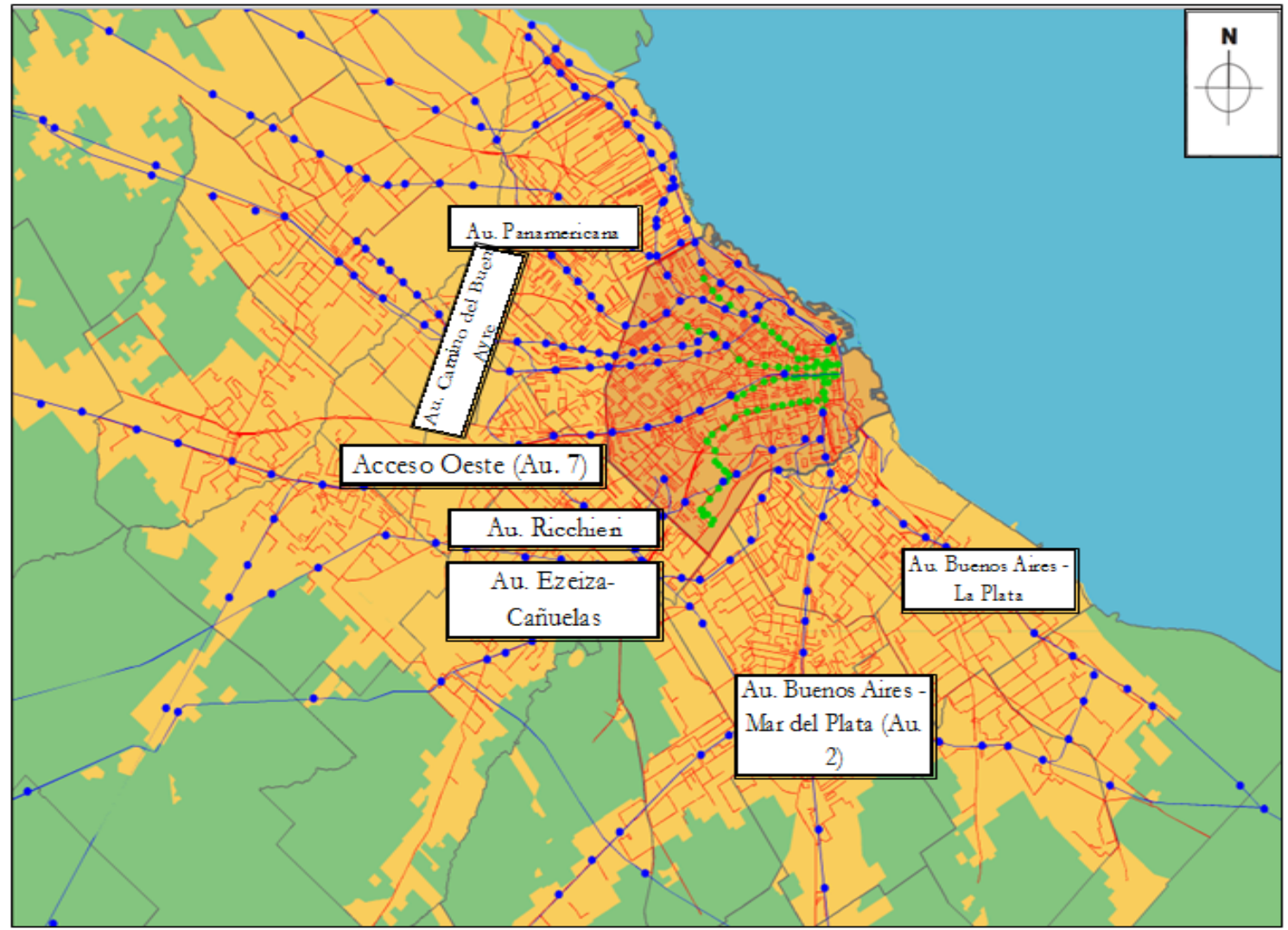

Fuente: Elaboración propia a partir de Atlas Ambiental de Buenos Aires (2013). 